Learning of the gods

\section{P.W. Atkins}

McGraw-Hill Encyclopedia of Chemistry.

Editor-in-chief Sybil P. Parker.

McGraw-Hill: 1984. Pp. 1,195. \$76.50,

f48.50.

Van Nostrand Reinhold Encyclopedia of Chemistry, 4th Edn.

Editor-in-chief Douglas M. Considine. Van Nostrand Reinhold: 1984. Pp. 1,082. $\$ 89.50, £ 95$.

Hermes Trismegistos, the Egyptian chemist (and god), was reputed to know everything and to have written it all down in 36,525 volumes. Latter-day Hermes must contend with publishers, pockets and profits, and must confine themselves to a 1,000 pages or so. But given that these two hefty volumes do summarize the present state of chemistry (a question we return to later), what impression would we take away from them about the range of the subject and its present achievements?

First, a few facts. The McGraw-Hill version (henceforth Hermes-M), cuts chemistry into about 800 pieces. The van Nostrand version (Hermes- $\mathrm{N}$ ), slices more finely, and ends up with around 1,300. Hermes-M is extracted from the fifth edition of the McGraw-Hill Encyclopedia of Science and Technology (1982). Hermes- $\mathrm{N}$ claims to be fully revised and much enlarged from the earlier editions, with about $90 \%$ of the material being new. Both Hermes wear the hats of specialist contributors from around the world; but while $\mathbf{M}$ ascribes every entry to its author, $\mathrm{N}$ is much more coy and many pages sometimes pass before a name appears. I very much prefer M's approach in this respect: it is helpful to see an attitude subscribed by authority, especially if it conflicts with a prejudice. Moreover, if a point seems questionable, it is useful to know that the apparent cross-support from another entry is written by another hand.

Quite different impressions of chemistry are obtained at first glance. Hermes- $\mathrm{N}$ is conventional in appearance with a somewhat muddy page; the line drawings are amateurish and poorly labelled. Hermes$M$, on the other hand, is much more striking in appearance, with a page that looks inviting, neatly tinted boxes displaying structures, and well-drawn illustrations. Both have quite good, but not perfect indexes, which are essential in works as big as these. Here $\mathrm{N}$ wins hands-

- Also newly published by McGraw-Hill is the McGraw-Hill Dictionary of Chemistry, containing terms and definitions selected from the third (1984) edition of their Dictionary of Scientific and Technical Terms. The chemical dictionary includes more than 9000 terms with emphasis on the vocabulary of theoretical and

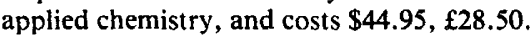

down, with around twice as many entries as M. The smaller count reflects M's lower density of cross-referencing; for example, "orbital" does not appear as such in $\mathbf{M}$, but has to be sought under "molecular orbital", which is not quite helpful enough, at least to a non-specialist.

It is once we move beyond first impressions that we get strikingly different visions of the present state of chemistry. From $\mathrm{N}$ it seems that a chemist is one who knows about sphene, spinel, spodumene and spray drying (to take a page at random). A page more typical of $\mathbf{M}$ contains secondorder transition and SIMS. Hermes-M knows not of spodumene and spinel. Hermes-N is free of SIMS.

Hermes- $\mathrm{N}$ is the traditional fellow, the god of foremen, plant managers, geologists and agriculturalists. $\mathrm{N}$ is largely the god of the technological chemist (who might understand his old-fashioned units). While $\mathrm{N}$ gives some helpful synoptic surveys of large fields (antibiotics for example), which are missing from $\mathbf{M}$, there

\section{Eminent lives}

\section{Christopher Spencer}

Biographical Dictionary of Psychology. By Leonard Zusne.

Aldwych Press, 3 Henrietta St, London: 1984. Pp.563. £47.50, \$49.95.

ABRAHAM, Karl (German psychoanalyst) to Zwaardemaker, Hendrick (Dutch otolaryngologist), but this is far from being just a dictionary of psychologists. Zusne has provided an excellent source of reference to the intellectual history of psychology: 544 brief biographies which, taken together, trace the development of ideas from Thales, Pythagoras and Heraclites, through the mediaeval scholastics and Arab philosophers, to the origins of modern science and the emergence of psychology as a distinct discipline.

Each entry has a common format: place and exact dates of birth and death; highest degree awarded; positions held; then several paragraphs describing and evaluating the work of the person concerned and its significance for psychology; and finally a bibliography of fuller biographies of the individual.

One can thus use the book as an historical encyclopaedia or browse with profit through the excellently-summarized biographies: Zusne shows that brief entries can be succinct without trivializing the subject matter. The volume will serve well as a sourcebook for amateurs in the history of science, expecially those interested in the cross-influences between disciplines, and includes an appendix which lists the nineteenth- and twentieth-century contributors to psychology by their principal university or institution. This appendix dramatically illustrates the Germanic domination of are some bizarre judgements. Why no mention, for instance, of NMR, probably the single most important physical technique available to chemists? Why six pages with do-it-yourself style diagrams on the fabrication of optical fibres?

Hermes-M, on the other hand, is a much more academic god. He seems to know little of traditional chemistry but a lot about spectroscopy, vinylogy and oscillating reactions. No nut-shell carbon for him.

For information about traditional chemistry, and particularly chemistry with a technological tinge, then Hermes- $\mathrm{N}$ is appropriate but a bit old-fashioned. For information about modern aspects of chemistry, with an up-to-date view of its current achievements, then Hermes- $M$ is undoubtedly the better source (and, at the price, the better value).

P.W. Atkins is a Fellow of Lincoln College and University Lecturer in Physical Chemistry at the University of Oxford.

nineteenth-century science, and the shift to American pre-eminence by the early twentieth century. Indeed, many individual biographical entries show that there was a movement of persons as well as ideas: Jastrow, Rapoport, Razran, Reich, Spitz and many others were born and educated in central and eastern Europe, but spent much of their working life in the United States.

Another appendix is perhaps of lesser value: Zusne takes up 16 pages with a table of "relative eminence", a ranking of all the contributors to psychology according to a count of pages devoted to each individual in 16 histories of psychology. Thus, in this table, Maslow beats by a short head St Albertus Magnus, who in turn ranks one place ahead of Kraepelin.

The only serious limitation of the book stems from Zusne's understandable reluctance to adjudicate between the relative claims of the living for inclusion in the Dictionary, and his consequent limitation of entries to the distinguished deceased. This imposes a curious selectivity of coverage of the subject. Thus, for example, Berlyne, Olds and Lenneberg, born in the $1920 \mathrm{~s}$, are eligible for inclusion because of their relatively early deaths; whereas many equally eminent figures of twentiethcentury psychology are still happily living, and thus ineligible.

This limitation on one side, the Dictionary is a welcome reference work. One final thought for our own over-productive age that remains with me, after several pleasurable hours of browsing, is that many of these biographies demonstrate that impact does not necessarily require a large output.

Christopher Spencer is a Lecturer in the Department of Psychology at the University of Sheffield. 